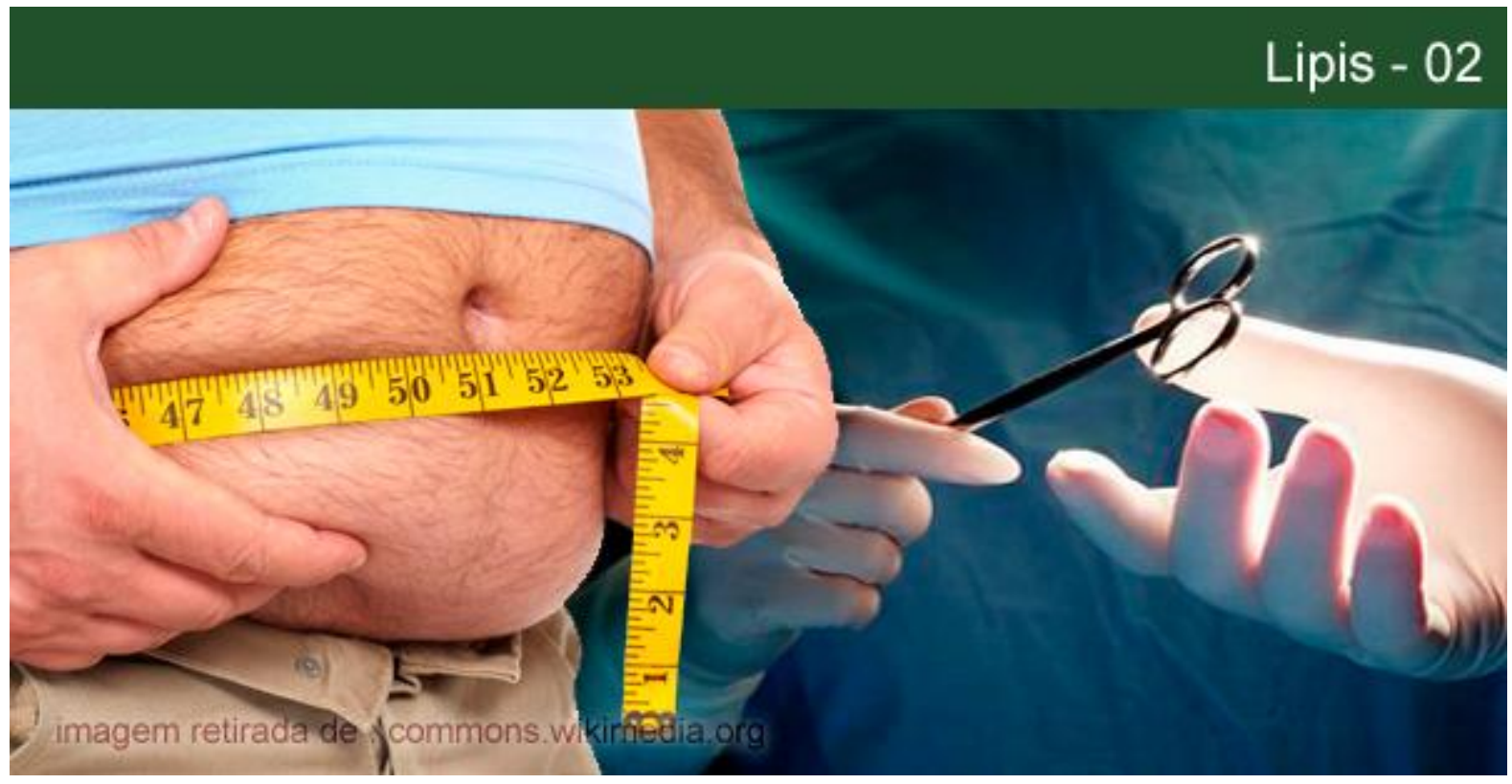

\title{
CORPO DE CONSUMO, CORPO CONSUMIDO: UMA EXPERIÊNCIA AMBULATORIAL NO ATENDIMENTO A PACIENTES DE CIRURGIA BARIÁTRICA
}

\begin{abstract}
Nelia Mendes
Mestre em Psicologia Clínica pela Pontifícia Universidade Católica do Rio de Janeiro (PUC-Rio). Graduada em Psicologia pela Universidade Federal do Rio de Janeiro (UFRJ). Pesquisadora do Laboratório Interdisciplinar de Pesquisa e Intervenção Social (LIPIS) da PUC-Rio. Psicóloga do Hospital Federal Servidores do Estado (HFSE/RJ). Membro em formação da Sociedade de Psicanálise da Barra (SPB). E-mail: neliamendes@gmail.com.

\section{Junia de Vilhena}

Psicanalista. Membro efetivo do Círculo Psicanalítico do Rio de Janeiro (CPRJ). Doutora em Psicologia Clínica. Professora do Programa de Pós-Graduação em Psicologia Clínica da Pontifícia Universidade Católica do Rio de Janeiro (PUC-Rio). Coordenadora do Laboratório Interdisciplinar de Pesquisa e Intervenção Social (LIPIS) da PUC-Rio. Membro do GT da ANPEPP "Psicanálise e clínica ampliada". Membro da Associação Universitária de Pesquisa em Psicopatologia Fundamental. Membro Associado da Euroscience Organization. Investigadora-Colaboradora do Instituto de Psicologia Cognitiva da Universidade de Coimbra. Pesquisadora correspondente do Centre de Recherches Psychanalyse et Médecine, CRPM-Pandora, Université Denis-Diderot Paris VII. E-mail: vilhena@puc-rio.br.
\end{abstract}

Resumo:A obesidade é uma pandemia na atualidade, objeto de estudo em diversas áreas. Na medicina, a cirurgia bariátrica é apresentada como uma técnica efetiva para o seu tratamento e controle. Na última década, assistimos a um aumento considerável no número de procedimentos realizados no Brasil. Neste artigo, buscaremos investigar a relação existente entre o sofrimento psíquico do indivíduo obeso e o estatuto do corpo na contemporaneidade, marcado progressivamente pela tecnociência e pelo biopoder. Procuraremos também refletir sobre as alterações psíquicas ocorridas no pós-operatório, quando a ingestão de alimento passa a ser limitada devido à redução do volume gástrico e à modificação de hábitos.

Palavras-chave: Obesidade.Cirurgia bariátrica.Sofrimentopsíquico.Corpo.Psicanálise.

\section{BODY OF CONSUMPTION, BODY CONSUMED: A PSYCHOLOGICAL OUTPATIENT EXPERIENCE WITH BARIATRIC SURGERY PATIENTS}

\section{POLÊM!CA $\mid$ LABORE (}

Polêmica - Revista Eletrônica da Uerj - Rua São Francisco Xavier, 524, $1^{\circ}$ andar

bloco D, sl.1001 • Tels.: +55 21 2334-4088 / 4087 • http://www.e-publicacoes.uerj.br/index.php/polemica/index http://www.labore.uerj.br • laboreuerj@yahoo.com.br 


\begin{abstract}
Obesity is currently a pandemic and an object of study in several fields. In medicine, bariatric surgery is presented as an effective treatment and control method. During the last decade we have seen a sharp increase in the number of procedures performed in Brazil. In this article we will try to investigate the existing relationship between the psychic suffering of obese patients and the contemporary status of the body, progressively shaped by technoscience and biopower. We will also try to reflect upon the psychic changes that may take place during post-surgery, when food intake is restricted due to the reduction of gastric volume and the alteration of habits.

Keywords: Obesity. Bariatricsurgery. Psychicsuffering. Body.Psychoanalysis.
\end{abstract}

\title{
Introdução
}

Fenômeno de análise e de intervenção em diversos campos do conhecimento humano, a obesidade desenvolveu-se de forma célere ao redor do mundo. No âmbito público deixou-se notar, sobretudo, pelas comorbidades a ela associadas que impactam severamente nos gastos com a saúde. As consequências econômicas da obesidade e doenças associadas não se limitam aos elevados custos médicos, mas incluem também os custos indiretos ou sociais, tais como: diminuição da qualidade de vida, perda de produtividade, dificuldades de ajuste social, incapacidade com aposentadorias precoces e morte (BAHIA \& ARAUJO, 2014).

No cenário nacional a progressão é análoga. Recente levantamento do Ministério da Saúde - VIGITEL (Vigilância de fatores de risco e proteção para doenças crônicas por inquérito telefônico), 2014 - confirma a disposição mundial e evidencia que a obesidade cresceu no país e atingiu percentual de $17,9 \%$ dos brasileiros. No entanto, quando o recorte é o sobrepeso, os dados são ainda mais significativos. Mais da metade da população brasileira (52,5\%) encontra-se acima do peso ideal quando considerado o que é preconizado pela Organização Mundial de Saúde (OMS) através do IMC (índice de massa corporal) - medida de referência internacional para o cálculo do risco de obesidade (BRASIL, 2014).

Assim, muitos são os esforços realizados pelas políticas públicas de saúde para a redução e minimização do impacto da obesidade na qualidade de vida e saúde dos indivíduos obesos. Dentro desta clave, a cirurgia bariátrica ou cirurgia de redução do estômago é descrita pela Sociedade Brasileira de Cirurgia Bariátrica e Metabólica (SBCBM) como uma técnica cirúrgica efetiva no controle da obesidade e das comorbidades a ela associadas (SBCBM, 2014). A indicação desta técnica é cada vez mais expressiva e está fundamentada na investigação abrangente dos vários aspectos que estão implicados.

Estudos longitudinais demonstram a eficácia da cirurgia bariátrica (RIOS MARTÍNEZ, 2012; LASAGNI, 2012; GORDON et al., 2011; ABESO, 2009-10). Taxas glicêmicas que se normalizam, níveis da pressão arterial que retornam a patamares

\section{POLÊM!CA $\mid$ LABORE}


compatíveis com a saúde física, redução de danos ósteo-articulares que resultam em maior mobilidade e disposição para as atividades da vida diária são alguns dos efeitos considerados e amplamente exaltados da redução do estômago.

Considera-se ainda, ao esquadrinhar a efetiva influência exercida pela cultura sobre o modelo de corpo ambicionado na atualidade, leia-se o corpo magro, que a cirurgia bariátrica pode também ser promotora de bem-estar em um sentido mais amplo, pois a obtenção desse corpo almejado representa mais do que ganho de saúde física ou estético, também é passaporte para o sentimento de pertencimento e aceitação social.

Em contrapartida, é possível afirmar que nenhum indivíduo que se submete à cirurgia da obesidade passa ileso de algum sofrimento (NÉSPOLI, NOVAES \& ROSA, 2015). As notáveis alterações no corpo proporcionadas pela cirurgia bariátrica tornam lícito supor alterações também psíquicas. Se ao tomarmos o eixo da medicina como paradigmático são incontestáveis os resultados positivos dessa cirurgia, sob o referencial da psicanálise o cenário não é tão auspicioso.

O exame da fase pós-operatória é profícuo em exemplos de vivências imersas em angústia e questionamentos. O desmoronamento da frequente crença inicial de que a cirurgia seria uma solução para além da perda de peso, também resolução de conflitos da esfera existencial, produz um rastro que conduz à imperativa necessidade de empreender pesquisas sobre o tema da cirurgia bariátrica e seus efeitos sobre o psiquismo.

Prescindir da obesidade e subjetivar a escolha pela cirurgia bariátrica implicam, desta forma, na reflexão sobre o porquê e para que o psiquismo organizou-se em torno do corpo pesado, nasimbolização deste corpo e na reflexão de como aquele sujeito específico que busca a cirurgia bariátrica tem se servido dele até então. Tarefa clínica ímpar e de grande monta que possui coadjuvância para o êxito do procedimento. Disto resulta o entendimento de que estamos no campo da clínica das heterogeneidades (PINHEIRO \& VILHENA, 2007), pois a obesidade é uma ocorrência que se coloca na prática clínica de forma bastante diversificada, demandando lançar no campo da subjetividade as reflexões sobre o tratamento.

Ancorados, portanto, na experiência clínica como psicóloga em uma equipe de cirurgia bariátrica de um hospital da rede federal na cidade do Rio de Janeiro, o presente artigo traz considerações teóricas e clínicas a partir de uma prática ambulatorial. Iniciaremos contextualizando o corpo e a contemporaneidade como aspectos que possuem determinante

\section{POLÊM!CA $\mid$ LABORE}


contribuição para o sofrimento psíquico e que motiva o paciente obeso a realizar a cirurgia bariátrica. Em seguida, refletiremos, igualmente, sobre as possíveis vicissitudes psíquicas da cirurgia bariátrica naqueles que a ela se submetem.

Como forma de ilustrar o trabalho, apresentaremos de forma bastante resumida, algumas falas representativas de pacientes que foram acompanhados neste ambulatório. Desta forma, buscamos auxiliar psicólogos e demais membros da equipe de saúde a lidarem melhor com as mudanças emocionais advindas do procedimento, possibilitando desenvolver intervenções de cuidado mais eficazes.

\section{Cultura do consumo e estetização da vida cotidiana - sob a égide do paradoxo}

Embora a obesidade não deva ser considerada uma psicopatologia per se, por estar intensamente ligada a causas orgânicas (MATTOS, 2007), é inquestionável sua potência como promotora de sofrimento psíquico e de alterações do modo como o sujeito se insere na cultura.

Coutinho (1999) destaca as mudanças de comportamento alimentar e os hábitos de vida sedentários como fatores que atuam sobre genes de susceptibilidade à obesidade e que desempenham determinante papel para o crescimento da obesidade no mundo. Desta forma, é provável que a obesidade surja como a resultante de fatores poligênicos complexos e um ambiente obesogênico.

Análises epidemiológicas em populações latino-americanas apresentam dados que demonstram que à medida que se consegue erradicar a miséria entre as camadas mais pobres da população, a obesidade avança como um problema mais frequente e mais grave que a desnutrição.

Chamado de transição nutricional, esse fenômeno sugere que por falta de acompanhamento e informação as pessoas estão passando da desnutrição para a obesidade, sobrecarregando o Sistema Único de Saúde com uma demanda crescente de atendimento a doenças crônicas relacionadas com a obesidade (BERG, 2011; BATISTA FILHO \& RISSIN, 2003; COUTINHO, 1999).

Ao mesmo tempo, neste cenário, observamos a valorização da beleza corporal associada à magreza como expressão verdadeira de saúde, produtividade e motor de desejo. Não obstante, essa valorização é potencializada pela "prescrição" dos discursos médico,

\section{POLÊM!CA $\mid$ LABORE}


midiático e da indústria da moda, que tornaram-se importantes articuladores do novo ideal estético que desencadeia práticas sociais que a todos subordina a serviço do próprio corpo. Um corpo transformado em objeto fetichizado, passível de consumo, mediado pelo seu culto e obsessão. Corpo alienado ao modelo narcísico da contemporaneidade e utilizado frequentemente como recurso social, uma vez que, nesse ideário, somos o que parecemos ser.

Alicerçados pelo aporte teórico de Baudrillard (1981), Debord (2003), Dufour (2009), Lasch (1983), Le Breton (2006, 2003) entre outros, é possível analisar as relações que a cultura estabelece com a corporeidade humana e a concepção de que o corpo é uma realidade construída socialmente e com múltiplos sentidos arquitetados pela cultura. Na concepção comungada por esses autores, o corpo está na intercessão de todas as instâncias da cultura e no fundamento de qualquer prática social. Ele é um dos objetos que assume valor simbólico expressivo na pós-modernidade e, desta maneira, esboçado em acordo com a noção de consumo e formação de novos mercados que é vigente. Se antes recalcado, hoje é posto em evidência e, nesta perspectiva, assimilado como prótese imagética a serviço do aprimoramento possível conferido pela tecnociência. Disto resulta o consumo cada vez mais expressivo da indústria comestológica, suplementação alimentar, cirurgias de reparação estética ou de "harmonização" das formas e (por que não também?) cirurgias bariátricas.

Baudrillard (1981) assinala a característica de consumo da sociedade atual que reduz o indivíduo a condição de consumidor com suas relações modeladas por esta prática. Para o autor, não consumimos mais coisas, somente signos que alimentam a sociedade forjada pela aparência. A insatisfação é, ela mesma, o incentivo que converte o indivíduo em um consumidor modelo sempre pronto a consumir outra promessa de plenitude e felicidade. Porém, a satisfação nunca é plena e nunca será. Neste projeto, pessoas felizes e satisfeitas não precisam mais consumir. Toda a "máquina" social funciona para que a satisfação seja sempre um advir.

O consumo é o trâmite necessário para reparar privações. Felicidade terceirizada por produtos a consumir que exigem, para sua obtenção, sacrifícios econômicos ou físicos. Como corolário, uma dependência socialmente autorizada e, desta forma, transformado na moral do mundo contemporâneo, o consumo atua como causa de inclusão, mas também, para aqueles que estão espontânea ou forçosamente à parte dessa lógica, como fator de estigmatização e exclusão.

\section{POLÊM!CA $\mid$ LABORE}


Debord (2003[1967]) sinaliza o impacto da moderna sociedade de consumo e sua incidência sobre as subjetividades. Crítica que se mantém muito atual a despeito do meio século que separa sua primeira publicação e o presente. Em sua instigante leitura, Debord destaca que a sociedade do espetáculo, na qual estamos todos submersos, diz respeito às relações sociais mediatizadas por imagens. O espetáculo é o cerne de uma sociedade pautada no irreal, onde o culto ao corpo e à aparência, a cultura da imagem e do consumismo ganham vulto e passam a ser valorados como norteadores de um bem viver.

Já as formulações de Lasch (1983) a respeito da cultura do narcisismo e sobre a personalidade narcísica da atualidade também são importantes ferramentas teóricas para encorpar a compreensão a respeito de como se engendram as novas formas de subjetivação na contemporaneidade, onde a grande busca é pelo ideal narcísico de perfeição.Também para a proposta deste trabalho que é a apreensão do sofrimento psíquico que motiva o obeso a se submeter a práticas de aprimoramento corporal, o autor nos presta grande contribuição.

Segundo Lasch (1983), o mundo estaria centrado no eu da individualidade, com o sujeito buscando sempre a estetização de si mesmo. Na análise empreendida pelo autor, os homens sempre foram egoístas e os grupos etnocêntricos, mas a ocorrência das desordens do caráter com as mais destacadas formas de patologia psiquiátrica é atribuída às mudanças de nossa sociedade e cultura. Por isso, menos do que culto ao privatismo que manifestações originárias da desintegração da vida pública, são o escopo da investigação do autor.

Em seu desenvolvimento teórico destaca o apuro em discutir a etiologia do narcisimo como sustentação de uma visão onde traços de caráter associados ao narcisismo podem ser explorados, oferecendo um melhor entendimento entre essas conexões. Assim, o intenso temor do envelhecimento, o fascínio pelas celebridades, as relações deterioradas entre homens e mulheres ou a obstinação pelo corpo que mascara transtornos alimentares sob a égide da saúde ou do investimento em qualidade de vida, que traz como presença o inefável sofrimento psíquico, são exemplos corriqueiros e, por isso, bem ilustrativos da íntima relação narcisismo e cultura.

Birmam (2014) também alude ao autocentramento do sujeito na atualidade e a cultura do narcisismo e do espetáculo, onde o que comparece como ponto nevrálgico é a exaltação gloriosa do próprio eu. A cultura da imagem é análoga à estetização do eu, na qual o sujeito vale pelo que parece ser. Sua importância é diretamente proporcional às curtidas em mídias

\section{POLÊM!CA $\mid$ LABORE}


sociais que recebe da personagem que forjou para si. Neste sentido, para Birman, a exigência sempre refeita de alto desempenho é marca do indivíduo na cultura do espetáculo e do narcisismo.

Nesta proposição, parecer algo ou ter coisas se amalgama com o ser, e afirma a marca inconteste narcísica da atualidade que demanda que o eu seja exaltado tal qual uma majestade, iluminado que é o tempo todo no palco da cena social (BIRMAN, p. 181). Desta forma, as psicopatologias da contemporaneidade estão marcadas pelo fracasso do indivíduo em realizar esta exaltação e estetização do eu.

O conceito de espetáculo unifica e explica uma grande diversidade de fenômenos visíveis que afirmam a aparência como capital. Assim, a obesidade, que outrora já esteve associada a valores positivados como a riqueza ou à saúde, atualmente está em posição oposta nessa escala imagética socialmente exaltada associada que está à doença e estigmas como os de feiura e infelicidade.

Ainda a propósito do corpo e da sociedade do espetáculo, Novaes (2013) reitera a perversidade do estigma da feiura, frequentemente associado com a gordura. Considera que a cultura da imagem ou, como a autora enfatiza, cultura cada vez mais tela e menos páginas, toma o lugar do próprio sujeito e torna-o estrangeiro em seu próprio corpo, alienado em si, pois existe somente como imagem (p. 59).

O corpo do homem é a própria imagem da cultura (REMAURY apud NOVAES, 2013), assim igualmente, problemas como uma má aparência, que é atribuída à obesidade, e que são concebidas como desleixo com o corpo, transgressão moral, falta de vontade, ou pior, de vergonha, inscreve como as formas de apreensão do corpo na atualidade se dão.

Em outros trabalhos, Novaes $(2013,2010)$ também traz uma expressiva contribuição ao perscrutar como se forjou essa representação estetizante do corpo na atualidade e se criaram as condições para a produção e disseminação dessa ideia. No interior da lógica do corpo de consumo tão própria da contemporaneidade, estar magra é fato valorizado em qualquer contexto social, sendo passe para a inserção. Ao obeso cabe o lugar menor, à margem do consumo.

A tirania do corpo ideal, entendida por muitos como um acesso à felicidade e todas as pequeninas coisas que dela fazem parte, está presente nos discursos de muitos dos pacientes de cirurgia bariátrica acompanhados no ambulatório. Ainda que réplica do discurso de saúde

\section{POLÊM!CA $\mid$ LABORE}


da disciplina médica, antecipa o desejo comum de possuir um corpo magro como autorização para a felicidade que é conquistada através do corpo socialmente positivado. Numa realidade em que o belo é o corpo magro, a impossibilidade de se ter esse corpo traz um sentimento de inferioridade e culpa (BERG, 2008, p. 118).

\begin{abstract}
"Acho que fazer essa cirurgia vai ser muito bom para mim... meu diabetes e minha pressão estão gritando. Vivo triste. Tenho vergonha do meu corpo. Não quero mais sair... W. me deixou. Tínhamos uma vida feliz, muito boa e cheia de conforto. Ele é moto taxi na comunidade. Estávamos sempre lanchando no Mc Donald's e no Habib's. Nunca fui magrinha, mas era do tipo gostosa. Comecei a engordar e ele foi me esculachando... Agora vive na moto com uma magrinha 'empuleirada' nela. Não quero mais viver assim, vou emagrecer e aí ele vai ver...” (J, 28 anos, pré-opertório)
\end{abstract}

Nesta visada, Le Breton (2006, 2003) corrobora a discussão ao considerar a construção do corpo como um fato social e cultural. Este se apresenta como objeto de representações e imaginários a partir da qual as relações com o mundo são construídas.

Este pensamento ampara a ênfase dada ao corpo como alicerce das relações com o mundo e como agenciador de subjetividades. Assim, o autor tece uma sofisticada teia na qual o corpo da atualidade comparece como lócus privilegiado de construção identitária fortemente intermediado pela tecnociência, modelado pelas exigências de um tempo e normatizado pelo biopoder, que submete os indivíduos à imolação das ideologias contemporâneas de aperfeiçoamento corporal.

Desta forma, absortos em um recorte cultural paradoxal na atualidade, na qual a sociedade é ao mesmo tempo obesogênica e lipofóbica, tornamo-nos interessados na escuta do sofrimento psíquico associado à obesidade. Este pode ser entendido como um reflexo dessa dupla direção, em que práticas e contexto econômico-social que propiciam o excesso de peso despontam lado a lado às exigências de padrões estéticos que se confundem, muitas vezes, com julgamentos morais. O obeso, neste cenário, é referenciado por suas formas que seguem em oposição aos ideais estéticos preconizados na atualidade. Convertidos na maior forma de exclusão socialmente validada como já fora sublinhado por Novaes (2010), os obesos são os "novos feios" a quem nenhuma crítica é poupada.

À obesidade o lugar do diferente. Diferença vivenciada no cotidiano uma vez que, inspirados no olhar de Le Breton acerca das deficiências (2006, p. 73) podemos dizer que o discurso social afirma que o grande obeso é um homem normal membro da comunidade, cuja dignidade e valor pessoal não são enfraquecidos por causa de sua forma física. No entanto, ao

\title{
POLÊM!CA $\mid$ LABORE
}


mesmo tempo, ele é objetivamente marginalizado, mantido fora do mundo do trabalho, afastado da vida social por causa das dificuldades de locomoção, assentos adequados e, sobretudo, vitimados por olhares de incômodo e de reprovação.

Em nossa sociedade, a obesidade é estigmatizada, sendo reservado a ela sutis ou ostensivas avaliações pejorativas de descrédito e escárnio. O diferente é socialmente transformado em estigma, em indício de imperfeição moral, colocando em xeque a precariedade da condição humana ao lembrar pelo poder da presença o imaginário do corpo disforme que assombra a muitos.

As reações provocadas no outro tecem uma tênue hierarquia do terror, que se expressam em maior ou menor grau, conforme o índice de omissão às normas de aparência física. Para Le Breton, quanto maior a derrogação a essas normas socialmente construídas, maior o horror e espanto declarado nas relações sociais (2006, p. 75). A forma ostentada pelo corpo passa a índice de qualidade das relações sociais que serão desenvolvidas.

\footnotetext{
"Hoje eu quero dizer que fiz sinal para o ônibus e entrei pela frente, passei pela roleta e me sentei. Ninguém ficou olhando para mim com aquele olhar de vai entalar. Isso é maravilhoso. Nem acreditei!!! Poder comprar a roupa que eu quero comprar. Fui na loja e pedi um número maior de uma bermuda... a vendedora disse que eu não era 50 e sim 48. Gente, isso é igual mastercard, não tem preço. Tô muito feliz!!!” (G, 38 anos, pós-operatório)
}

A reflexão em torno do discurso normatizador do corpo que estabelece mimetismo entre a magreza e a beleza, símbolo da nossa contemporaneidade hedonista, possui aqui destacada relevância porque contribui de forma indelével para a cada vez maior utilização de procedimentos médicos e intervenções cirúrgicas corretivas e estéticas como saída para um mal-estar. Saroldi (2011) propõe que aqueles que por conta de sua própria constituição não conseguem concordar com as limitações a que são submetidos na cultura tornam-se outsiders diante da sociedade. Sentimento frequentemente relatado por muitos pacientes.

De fato, Freud já introduzira em 1908 no texto "Moral sexual civilizada e doença nervosa moderna", que o agenciador do mal-estar era a moral presente na modernidade e os impasses derivados da impossibilidade de sublimação das pulsões em um grande número de pessoas. Estas seriam as condições de possibilidade das perturbações nervosas. Havia uma relação direta entre o aumento do número de doenças nervosas e o aumento do número de restrições sexuais da época. Acrescenta Birman (2012, p. 60) que a moral incidiria

\section{POLÊM!CA $\mid$ LABORE}


efetivamente sobre a erótica das individualidades, impondo, assim, restrições e imperativos tão insuportáveis que seriam capazes de perturbar o funcionamento do espírito.

Claro está a mudança sofrida nas subjetividades e no discurso social atual quando comparados à época vitoriana de Freud. Do supereuinterditor do gozo a um supereu mandante que determina que se goze a todo instante (SAROLDI, 2011), do modelo do recalque para o modelo centrado na felicidade, no culto do eu e no prazer, estamos diante de um tipo estranho de satisfação que não leva em conta os interesses de preservação do eu e que incita o sujeito a ir além do seu bem-estar.

Nas palavras de Dufour (2009[2010]), uma nova economia psíquica está se constituindo e é mister estar sensível a estas modificações que o social e a lógica do mercado liberal impõe. Ao não reprimir as pulsões, o mercado passou a oferecer aos consumidores todos os objetos possíveis e inimagináveis para satisfação dos desejos com a promessa de felicidade e "salvação" pelo crescimento infinito de riquezas. Se em Freud (1930) a civilização só poderia se desenvolver às expensas da renúncia pulsional, eis que no princípio liberalista vigente, a repressão das pulsões não é mais necessária. Para Dufour (2009[2010]), então, é este o motivo exato de como a economia do mercado atinge a economia psíquica.

No pensamento deste importante filósofo contemporâneo, o fundamento liberalista promove a saída do enquadre freudiano clássico da neurose e a entrada em um enquadramento pós-neurótico no qual predominam a perversão, a depressão e o vício. Estes são a consequência lógica de um mundo que promete a satisfação pulsional generalizada e oferece sempre um produto, um objeto, um fantasma, capaz de satisfazer qualquer que seja o apetite.

Assim, assistimos ao desmonte de uma economia do desejo e sua substituição por uma economia do gozo que rejeita a castração e evidencia o engano de que a satisfação da demanda é equivalente a satisfação do desejo. A incidência da lógica implícita de que é o objeto que mostra o que falta ao sujeito e não a falta do sujeito que o dirige ao objeto, que é tão própria a contemporaneidade, produz para Dufour consequências na esfera social gerando o fenômeno da segregação, do racismo e da violência.

Campos (2011) propõe uma interessante articulação entre a obesidade e a subjetividade, apontando formações culturais que tornam a obesidade uma expressão da fetichização do corpo na modernidade.

\section{POLÊM!CA $\mid$ LABORE}


Em sua perspectiva de trabalho, procura a compreensão do sofrimento associado à obesidade como fenômeno psíquico. Desta forma, destaca que o sujeito obeso é também um sujeito de fala; como tal, a expressão do seu sofrimento pode ou não estar construída tendo a obesidade como significante.

Ainda neste artigo, Campos apresenta um modelo de análise onde o sujeito sofre a influência de frustrações e cobranças sociais, as quais acionam mecanismos que levam ao comer em demasia. Para fazer frente ao corpo opulento, adota o emagrecimento como solução, associando perder peso a aceitação social, tornar-se belo e feliz. Ao mesmo tempo, a indústria da moda, a cultura do consumo e a mídia formam o trio perverso, que veicula as fantasiosas soluções para ter acesso rápido e, muitas vezes, mágico ao emagrecimento, que representa em última análise, a meta de ser belo, feliz e localizado no olhar do Outro.

A partir daí, pode ser observado o quanto que a perda de peso desvinculada de um olhar para as causas que concorrerão para seu acúmulo tende a ineficiência, claro que fica que insatisfações e frustrações podem não desaparecer com a gordura perdida. Os esforços empreendidos são percebidos como inúteis, alimentando um insidioso ciclo de vergonha e culpa que tem como resultado a retomada da compulsão como solução. Quer a compulsão para comer como promotora de alívio e apaziguadora do mal-estar, quer a compulsão por emagrecer recorrendo a toda e qualquer ordem de coisas.

Nesta concepção disponibilizada, a obesidade não é ou deve ser tratada como um sintoma, pois não há tal coisa como psicopatologia da obesidade. Porém, ela pode ser entendida como uma expressão de diferentes formas de subjetivação.

A obesidade, assim, tem valor de significante, que toma monta de fala quando pode ser lida como manifestação do sofrimento em torno do corpo pesado e em torno de sua invisibilidade para o mundo, paradoxalmente, que se faz notar justo pela visibilidade do mesmo ou em torno da relação estabelecida com a comida.

A subjetividade é assim a resultante do esforço do sujeito de construir verdade sobre si e sobre o mundo, dentro de uma cultura estabelecida. Nesta leitura, corroborando o disposto por Novaes $(2013,2010)$, os meios de comunicação reforçam o ideal definido de beleza que nutrem os transtornos e oferecem significantes culturais do magro-belo e do gordo-feio, e que sob a inspiração midiática perversa, e porque não também das ciências médicas, o gordo é

\section{POLÊM!CA $\mid$ LABORE}


relacionado ao infortúnio. A felicidade depende diretamente dos padrões ofertados culturalmente e, em nome da obtenção dessa tal felicidade, muitos sofrem e se sacrificam.

Apropriando-nos da lógica darwinista que estabelece que indivíduos que melhor se adaptam ao meio tem maiores chances de sobrevivência do que os menos adaptados, poderíamos pensar que os indivíduos capazes de realizar variações favoráveis às condições do ambiente onde vivem têm maiores chances de sobreviver. Assim, a busca pelo emagrecimento pode ser compreendida, em última instância, como símbolo dessa sobrevivência e resistência aos ataques morais que angustia a tantos, em uma espécie de eugenia estética.

Se somos o que parecemos ser, se somos valorados pelo que possuímos, se a imagem vale mais do que a palavra, como querem as campanhas publicitárias, o corpo é palco privilegiado de expressão do sentimento gregário que ampara a condição humana. Então, finalmente emagrecidos, sentiremo-nos parte do grupo, da coletividade e teremos a garantia de cidadania.

É esse o destaque dado no discurso dos pacientes que frequentam o ambulatório de psicologia no qual esse trabalho se originou. $\mathrm{O}$ corpo que se apresenta à cena no hospital em um primeiro momento é certamente aquele que padece pelo diabetes, hipertensão ou algo equivalente. No entanto, a escuta sinaliza que é o sofrimento psíquico fusionado a experiência da obesidade que se quer erradicar. Ser magro é, em nossa cultura, garantia de acessibilidade no sentido mais plural e em prol da obtenção do que deveria ser inalienável, ou seja, o exercício de direitos e deveres em uma sociedade, verdadeiros desvarios, molas para mais sofrimento, são cometidos.

Embora homens também sejam atingidos, são as mulheres que comparecem em maior número ao ambulatório solicitando a redução do estômago. Sabe-se que, historicamente, os homens negligenciam o cuidado com a saúde. Porém, na perspectiva aqui colocada, ser bela é pressuposto categórico para a mulher, que fica em posição de maior vulnerabilidade às pressões sociais que estimulam os preconceitos. Talvez aí estejam assentadas as bases para o sofrimento psíquico, transtornos alimentares, ansiedade e depressão prevalentes no universo do qual tratamos no hospital.

\section{Cirurgia bariátrica - uma panaceia existencial?}

\section{POLÊM!CA $\mid$ LABORE}


“E hoje faz 3 anos que operei. Me arrependo de não ter operado antes. Não foi fácil. Ainda não é.... Todo dia tenho que ser vigilante para não ganhar peso de novo. $\mathrm{E}$ muitos dias tenho que me debater para não ser engolida pela vontade de comer mais ou o que eu não devo. Mas é isso mesmo... existe a tal cabeça de gordo. O estômago é pequeno, mas a cabeça... Digo uma coisa para vocês: 'se vocês não mudarem a cabeça, é melhor nem fazer. O Dr. D. opera nosso estômago, mas continuamos os mesmos. Só que agora com um estômago reduzido. Se não mudar, se não fizer diferente, as chances de não dar certo são bem grandes"” (G., 34a).

O pequeno relato que inaugura esta sessão é cada vez mais frequente na prática clínica como psicóloga da experiência em questão. Passados 5 anos da constituição da equipe multidisciplinar, o trabalho ganhou em unidade que pode ser percebida no discurso da equipe replicado pelos pacientes de que a cirurgia só representa uma solução se puder vir acompanhada de novas atitudes frente à vida.

Desta forma, ressalta-se que a cirurgia bariátrica está longe de ser uma solução milagrosa para o sujeito e que é necessário muito empenho para alçar bons e efetivos resultados. Assim, a nova identidade corporal não é desprovida da percepção de que outras transformações se fazem necessárias (VILHENA, NOVAES \& ROCHA, 2008) e que para prescindir da obesidade é preciso implicar-se na busca de sentidos para este corpo.

No entanto, uma interrogação persistia e insistia, talvez como metonímia do conceito psicanalítico que designa - a pulsão. A habitual referência ao uso excessivo ou abusivo da comida em situações que remetem para o mal-estar psíquico, comumente relatados sobre as roupagens de ansiedade ou depressão, antecipava a indagação do que aconteceria no momento em que, após a cirurgia e quando atravessando mares revoltos nos quais todos nós somos lançados em nosso cotidiano, não pudessem mais contar com o ancoradouro tranquilizador outrora utilizado.

Em uma resposta rápida há de se desenvolver novos atracadouros. No entanto, por certo, a solução rápida também revela o laborioso trabalho que é constituído no um a um e na escuta diligente que particulariza e subjetiva cada história trazida pelos pacientes deste ambulatório. Em tese, técnicas cirúrgicas, IMC, comorbidades e motivações para a cirurgia compartilhadas, mas talvez seja apenas isso.

Retomamos o argumento de muitos pacientes de que comem por ansiedade e o implícito movimento de vai e vem descortinado quando o alívio experimentado com a ação específica de comer é fortuito, inaugurando nova - será mesmo nova? - experiência de

\section{POLÊM!CA $\mid$ LABORE}


desprazer. Igualmente, prosseguimos com o exame das vicissitudes psíquicas frente à restrição do uso amplo do objeto eleito no pós-operatório da cirurgia em questão.

"Percebi que alguma coisa não ia bem quando vi que esperava minha mãe sair para trabalhar e saía logo atrás para o comércio. Se antes eu comia escondido, agora eu compro escondido. Compro todas as miudezas que vejo porque não posso aparecer em casa com um monte de coisas novas... Elástico de cabelo, bijuterias, maquiagem." (M. 28a)

"Ninguém me disse que eu ia emagrecer esse tanto. Olha como eu tô!!! Cheia de pelancas. Pareço uma caveira. Fiquei velha... não posso mais colocar uma camiseta, não posso mais colocar uma saia. Fica essa muxiba à mostra. Horrível! Não sei como essas mulheres fazem cirurgia e dizem que estão bem ou sentindo-se bonitas. É tudo mentira. Tenho vontade de falar para todas elas que não façam porque vão se arrepender... Meu marido perdeu o interesse em mim. Estamos mal. Quase separados... não consigo comer direito. Enjôo, vomito. Já precisei reinternar várias vezes por anemia. Tenho vontade de dormir e não acordar. Estar acordada é muito triste para mim, sabe? Outro dia, tomei tanto tranquilizante... me levaram para o pronto socorro. Lá disseram que eu tentei suicídio. Mas não, não foi isso. Só quero dormir. Depois dessa cirurgia tudo piorou. Se eu soubesse que seria assim... não teria feito mesmo". (T. 48a)

"Estou agora com o corpo que sempre sonhei. Já vou para minha terceira cirurgia reparadora. Fiz abdome, braços. Agora quero retirar o excesso de pele das coxas e depois colocar silicone no busto. Estou bem feliz. Mas, tem uma coisa que me incomoda e que me deixa muito triste. As mulheres na igreja agora ficam me olhando de cara feia... soube que espalharam que tenho um caso com o pastor... Ele sempre me ajudou. Mas, agora, só porque estou magrinha, tenho sofrido este tipo de injúria. Acho que elas pensam que vou roubar o marido delas. Seria incapaz disso" (L. 47a)

É em 1915, em "Pulsões e seus destinos", que Freud expõe sistematicamente o conceito metapsicológico da pulsão (ou trieb), fundamental para a teoria psicanalítica e para a abrangência das questões postas.

Em seu apuro teórico, Freud aponta neste texto os caminhos para que o representante ideativo (vorstellung) da pulsão encontre sempre a satisfação, ainda que indiretamente, através dos objetos. A tais caminhos para a obtenção da satisfação, Freud assinalou também como variantes defensivos contra as pulsões, que por sua natureza insistem insidiosamente, como uma medida de exigência feita à mente no sentido de trabalhar em consequência de sua ligação com o corpo (FREUD, 1915, p. 127).

Ainda no âmbito da primeira tópica, Freud descreve as vicissitudes das pulsões sexuais. Desta maneira, reversão a seu oposto, retorno em direção ao próprio eu, a sublimação e a repressão são os destinos possíveis indicados.

\section{POLÊM!CA $\mid$ LABORE}

Polêmica - Revista Eletrônica da Uerj - Rua São Francisco Xavier, 524, $1^{\circ}$ andar

bloco D, sl.1001 • Tels.: +55 21 2334-4088/4087 • http://www.e-publicacoes.uerj.br/index.php/polemica/index

http://www.labore.uerj.br • laboreuerj@yahoo.com.br 
A reversão a seu oposto, para Freud, se explicita com a ideia de algo que circula e que ao circular, inverte o sentido. Tanto pode ser o sentido do objetivo - da passividade para a atividade - ou do conteúdo - mudança do amor em ódio (GARCIA-ROZA, 1995, p. 121).

No que diz respeito ao segundo destino da pulsão, o retorno em direção ao próprio eu do indivíduo, Freud aproxima ao destino anterior ao apontar uma convergência de processos. O masoquismo é, na realidade, o sadismo que retorna em direção ao próprio ego do indivíduo, e o exibicionismo abrange olhar para o próprio corpo. A essência do processo é, assim, a mudança do objeto, ao passo que a finalidade permanece inalterada (FREUD, 1915, p. 132).

No tocante a sublimação, Freud aponta que ela diz respeito a modificação da meta. É um desvio da pulsão do seu objetivo sexual em direção a outros objetivos que não apresentem uma relação aproximada com o sexual. Não se trata, portanto, de uma exclusão da satisfação, mas de uma das modalidades possíveis de obtenção da mesma. É esse desvio quanto a meta que Freud aponta como o mecanismo central de sublimação. A satisfação é obtida por um desvio de seu alvo inicial, de modo que ela seja alcançada em outro lugar. Desta forma, implicando em uma dessexualização do objeto e, por conseguinte, do próprio alvo.

A essas considerações, soma-se a contribuição de Garcia-Roza (1995) ao reiterar que para Freud, a sublimação trata-se da pulsão de "alvo inibido", isto é, de processos nos quais há um avanço no sentido da satisfação mas ao mesmo tempo uma inibição ou um desvio desse alvo (p. 133). Não impedindo, contudo, que haja uma satisfação parcial, possível graças à maleabilidade das pulsões. Caso exemplificado pelas artes e literatura.

O recalque também, como referido, é destino de uma moção pulsional. Como assinalado por Freud no texto sobre o recalque em 1915, uma das vicissitudes que a pulsão pode sofrer é encontrar resistências que procuram torná-lo inoperante. Isto porque o caminho em direção a satisfação pode provocar mais desprazer do que prazer. Aqui o aspecto econômico se anuncia e é levado em consideração.

Em princípio, a satisfação da pulsão é sempre considerada como prazerosa, porém pode ser considerada como inconciliável com exigências feitas a partir de uma das instâncias psíquicas. Desta forma, o que produz satisfação em uma instância pode ser considerado desprazeroso na outra. O recalque também está a serviço da satisfação pulsional. No entanto, a satisfação se dá indiretamente por intermédio dos sintomas.

\section{POLÊM!CA $\mid$ LABORE}


Uma digressão aqui se faz necessária para melhor respaldar a trilha investigada. Desde os textos metapsicológicos iniciais, Freud (1905) sustentava que o chuchar ou sugar já são características essenciais da manifestação da sexualidade infantil. Na fantasia do bebê, o dedo é o substituto do seio materno e, sendo assim ao sugá-lo, ele não mais depende do outro para a sua satisfação. Esta que inicialmente é autoerótica, com o curso do desenvolvimento psicossexual, será dirigida a objetos externos, o que implicará em modos distintos de relação com estes em cada nova fase que se sucede.

A oralidade é a primeira fase que evidencia que as relações primordiais da criança com a mãe implicam em um plano não restrito à satisfação de suas necessidades vitais. Com isto, em Freud, a vivência de satisfação prototípica da fixação do desejo em um determinado objeto, é uma experiência oral. Desejo e satisfação estão marcados por essa primeira experiência, pois parte das pulsões sexuais ao longo do seu desenvolvimento pode permanecer fixada às pulsões de autoconservação.

Assim, se uma importância erógena da zona labial permanece mais acentuada na vida adulta, ela pode conduzir ao consumo de bebidas, ao excesso de fumar ou do comer (GURFINKEL, 2011).

Abraham (1916) ratifica a posição freudiana ao afirmar que elementos da sexualidade infantil que são excluídos da participação na vida sexual do adulto em parte se transformam em certos traços de caráter. Desta forma, o erotismo oral é também uma fonte de formação do caráter e, a travessia bem sucedida por esta etapa, constitui o primeiro passo - e talvez o mais importante - em direção a uma atitude satisfatória nas relações sociais e sexuais do indivíduo. O aforismo é consolidado pela ideia de que a oralidade forma a base sobre a qual se assenta o prazer de tomar e receber algo.

Imerso nas balizas de Abraham, Gurfinkel (2011) irá afirmar que qualquer perturbação nesta experiência inicial de receber tem consequências para todo o desenvolvimento libidinal ulterior, levando particularmente a um sadismo acentuado, que teria como fonte ou a carência ou um excesso de prazer oral.

Complementa o autor, revelando que um dos traços mais distintivos derivados da privação acentuada do erotismo oral é o que denominou "exigência agressiva" de gratificação dirigida ao objeto, constituindo o que poderia ser denominado "uma relação de oralidade com o objeto", frequentemente encontrados em indivíduos adictos (p. 304).

\section{POLÊM!CA $\mid$ LABORE}


Vilhena, Novaes e Rocha (2008, p. 398) apresentam considerações a respeito da clínica com indivíduos obesos que revelam uma psicodinâmica semelhante a dos drogaditos. Uma associação que parece já ter sido percebida pelo saber popular, pois os obesos mórbidos estão sendo apelidados de heavy users, algo como "consumidores pesados", expressão tradicionalmente usada para usuários de drogas. Questionam assim, se a cirurgia teria sozinha a capacidade de interromper o uso compulsivo da comida, no que elas chamaram de um curto-circuito da passagem ao ato.

A interrogação nos parece bastante apropriada e pertinente uma vez que a restrição mecânica, ocasionada pela gastroplastia, não necessariamente impede o uso aditivo da comida ou a vigência de outros comportamentos para burlar tais limites, como o uso exacerbado de bebidas alcoólicas, compulsão por compras e outros.

Abraham apud Gurfinkel (2011), a despeito das orientações de Freud para que empreendesse maiores estudos na área da anorexia histérica, dedicou-se mais ao estudo da compulsão alimentar do que ao seu negativo - a anorexia -, postulou a "fome neurótica", como um sentimento anormal de fome que surge em intervalos irregulares, que não guarda qualquer relação com a fome fisiológica e que surge acompanhada de grande mal-estar e ansiedade.

O recurso à alimentação impulsiva ou compulsiva pode ser uma tentativa de defesa, ao proporcionar uma sensação de preenchimento que traz grande alívio. A gênese deste impulso exagerado para comer provém de fontes libidinais reprimidas. Compreendemos desta forma que, assim como na toxicomania, também na compulsão alimentar, o objeto da adicção serve como satisfação substitutiva de uma atividade libidinal inibida.

Segundo as proposições de Abraham o comportamento dos pacientes que anseiam por comida em curtos intervalos e passam por torturas se seus desejos não são satisfeitos, é extraordinariamente similar ao dos morfinômanos e de uma boa quantidade de dipsomaníacos $^{1}$ (p. 329).

Expandindo a possibilidade de compreensão do fenômeno, Gurfinkel (2008) propõe o deslocamento do eixo pulsional da satisfação oral até aqui explorado a partir da contribuição de Abraham para a problemática da relação com o objeto.

\footnotetext{
${ }^{1}$ Necessidade incontrolável de ingerir bebida alcoólica.
}

\section{POLÊM!CA $\mid$ LABORÉ}


A exacerbada fixação no objeto encontrada nas toxicomanias e nas adições, que pode ser compreendida como única fonte de prazer para o indivíduo, supõe que a comida é, para o comedor compulsivo, uma espécie de objeto-fetiche.

Nota-se, entretanto, que não há uma relação bem estabelecida entre a aderência da libido e a história do indivíduo. As trocas de objeto de eleição para o "consumo" apontam para a hipótese que a adição é a repetição compulsiva destituída de qualquer sentido simbólico. Pura promoção de um efeito entorpecente e alienante, que além de objetivar o prazer visa também evitar a angústia e o sofrimento.

Ao problematizar a reversão lógica do conceito de apoio expresso nos casos das adições, expandimos a construção para a compreensão também da compulsão alimentar, onde a indagação repousa sobre como compreender a conduta do compulsivo, se do lado da sexualidade ou da autoconservação?

Gurfinkel (2008, 2011), permanecendo restrito ao disposto na primeira teoria das pulsões, assevera o vínculo particular estabelecido com o objeto em que este passa a se tornar uma questão de sobrevivência, realmente necessitado como uma droga para a manutenção do equilíbrio.

Desta maneira, a expressão empregada por Gurfinkel (2011) "metamorfose pulsional” anuncia que a pulsão sexual busca assumir o funcionamento da pulsão de autoconservação, recolocando o universo do desejo no plano da necessidade, deslocando o modelo da pulsão sexual para o da necessidade (p. 344 -7).

O regresso ao registro da necessidade aponta para o curto-circuito da passagem ao ato citado por Vilhena, Novaes \& Rocha anteriormente, uma vez que, a exigência de trabalho imposta ao psíquico implica na impossibilidade de promover um hiato. Como o pensamento impede a ação, neste plano, a conduta compulsiva elimina justamente a capacidade de promover uma escansão.

Na obesidade mórbida, além do sofrimento inegável encontramos uma dimensão de gozo. Diferente do prazer, o gozo refere-se a um "mais-além" do princípio do prazer. O gozo absoluto é a morte, aquém deste há gozos parciais e possíveis. O sujeito passa a vida funcionando de acordo com os pontos de condensação de seu gozo, o que lhe dá, digamos, algo como uma identidade, daí a dificuldade dele abrir mão disso, desse modo de gozar. Dificuldade que o obeso mostra claramente. E esses pontos enigmáticos de condensação retornam continuamente na compulsão que os caracteriza. Mas os pacientes se fiam na medicina para resolver, ou mesmo decifrar, sua obesidade, buscando soluções fora deles. Pode haver aí uma cilada,... O corte da cirurgia parece apontar para uma verdadeira passagem: a vida "antes" e a vida

\section{POLÊM!CA $\mid$ LABORE}

Polêmica - Revista Eletrônica da Uerj - Rua São Francisco Xavier, 524, $1^{\circ}$ andar

bloco D, sl.1001 • Tels.: +55 21 2334-4088/4087 • http://www.e-publicacoes.uerj.br/index.php/polemica/index

http://www.labore.uerj.br • laboreuerj@yahoo.com.br 
"depois". Os médicos são postos no lugar de mestre, mas só podem atuar naquilo que aparece. Não possibilitam, necessariamente, acesso ao que há de subjetivo, de desejo e de gozo no laço com a comida, enfim, ao que há do sujeito na construção da obesidade mórbida bem como no seu movimento rumo à cirurgia bariátrica. (VILHENA, NOVAES \&ROCHA, 2008, p. 398).

\section{Conclusão}

As considerações teórico-clínicas aqui apresentadas possuem como cenário o hospital geral. A acepção de um lado inconsciente, por vezes ininteligível, que é parte essencial do psiquismo e gerador de conflitos e queixas que podem complicar evoluções ou reduzir a eficácia da terapêutica prevista (ROMANO, 1999) é de conhecimento amplo de médicos e demais profissionais que compõem uma equipe de saúde. Desta maneira, é sabido que os aspectos psíquicos que permeiam toda e qualquer experiência de um indivíduo podem alterar as reações, modificar a adesão ao tratamento e interferir na tomada de decisões que influenciarão o sucesso de um determinado procedimento médico proposto.

É no campo da compreensão do que não está manifesto, mas que abala a experiência do sujeito diante do processo saúde/doença que vigorará a possibilidade de atuação e contribuição do psicólogo como parte integrante das equipes de saúde.

A obesidade é um fenômeno que, por seus efeitos deletérios, polariza a atenção de profissionais da área da saúde. Assim como também diversos outros profissionais de distintas áreas, que são convocados a pensar em seu grande impacto social e econômico no sentido de minimizá-los.

A cirurgia bariátrica é o recurso considerado padrão ouro para o tratamento da obesidade mórbida, sobretudo quando outros recursos de tratamento resultaram em insucesso. De fato, suas consequências no âmbito da saúde são notórias e notáveis. No entanto, ao tratarmos de seus efeitos sobre o psiquismo, a relação de sucesso nem sempre é tão direta.

A expectativa fantasiosa de que a cirurgia bariátrica representa um elixir capaz de salvaguardar as pessoas que a ela se submetem das dores da alma, deve ser exaustivamente trabalhada e combatida tanto no período anterior quanto no pós-cirúrgico, pois esta representa passo importante para a não adesão a nova proposta de vida que a cirurgia exige.

Poderíamos pensar qual a satisfação possível após a cirurgia. A pulsão, por sua natureza sempre insistente, encontrará, de certo, novos caminhos para se expressar. Caudalosos ou não. Acompanhar a relação que cada sujeito estabelece com seu corpo e os

\section{POLÊM!CA $\mid$ LABORE}


sentidos que formula para o uso irrestrito do alimento é a aposta realizada no ambulatório de psicologia na busca por novos atracadouros.

\section{Referências}

ABRAHAM, K. O Primeiro Estágio Pré-Genital da Libido (1916). In: ABRAHAM, K. Teoria Psicanalítica da Libido - Sobre o Caráter e o Desenvolvimento da Libido. Rio de Janeiro. Imago Editora, 1970.

ASSOCIAÇÃO BRASILEIRA PARA O ESTUDO DA OBESIDADE E DA SINDROME METABÓLICA ABESO. Diretrizes brasileiras para a obesidade- 2009/10. Disponível

em:<www.abeso.org.br/pdf/diretrizes_brasileiras_obesidade_2009_2010>.Acesso em: 18 jun. 2015.

BAHIA L. R.; ARAÚJO D.V. Impacto Econômico da Obesidade no Brasil. Revista Hospital Universitário Pedro Ernesto, 13(1):13-17, 2014.

BATISTA FILHO, M.; RISSIN, A. A transição Nutricional no Brasil:tendências regionais e temporais.Cadernos de Saúde Pública, Rio de Janeiro,v. 19, suplemento 1, 2003, p181-191.

BAUDRILLARD. J. A Sociedade do Consumo. São Paulo: Martins Fontes, 1981.

BERG, R. Uma Análise Freudiana da Obesidade. Dissertação de Mestrado, Programa de Pós-Graduação em Saúde e Desenvolvimento Humano, Instituto de Psicologia. Universidade de São Paulo, 2008.

. Medicina, Freud e obesidade: diálogos multidisciplinares sob a perspectiva de Foucault. Ágora (Rio J.), Rio de Janeiro, v. 14, n. 2, p. 183-196, Dec.2011. Disponível em:

<http://www.scielo.br/scielo.php?script=sci_arttext\&pid=S1516-14982011000200002\&lng=en\&nrm=iso>. Acesso em: 15 nov. 2014.

BIRMAN, J. Mal Estar na Atualidade - A psicanálise e as novas formas de subjetivação. Rio de Janeiro: Civilização Brasileira, 2014.

.O Sujeito na Contemporaneidade. Rio de Janeiro: Civilização Brasileira, 2012.

BRASIL. Ministério da Saúde. Vigitel Brasil 2014: vigilância de fatores de risco e proteção para doenças crônicas por inquérito telefônico. Brasília: Ministério da Saúde, 2014.

CAMPOS, D. T. F. A Repetição e o Par Mania-Depressão na Clínica Psicanalítica das Obesidades. Revista MalEstar Subjtividade. Fortaleza, v.11, n. 2, 2011. Disponível em:

$\langle$ http://pepsic.bvsalud.org/scielo.php?script=sci_arttext\&pid=S1518-1482011000200003\&lng=pt\&nrm=iso>. Acesso em: 13 set. 2015.

COUTINHO, W. F. O Consenso Latino Americano em Obesidade. Arquivos Brasileiros de Endocrinologia e Metabologia, 43(1),21-67, 1999.

DEBORD, G. A Sociedade do Espetáculo. Contraponto Editora, 1997.

DUFOUR, D-R. O Divino Mercado. Cadernos Psicanalíticos - CPRJ, Rio de Janeiro, ano 32, n. 23, p. 55-66, 2010 [2009].

FREUD,S. Os Instintos e suas Vicissitudes (1915). In: . Edição Standard Brasileira das Obras

Psicológicas Completas de Sigmund Freud. Rio de Janeiro. Imago Editora, V. XIV, 1996.

\section{POLÊM!CA $\mid$ LABORE}

Polêmica - Revista Eletrônica da Uerj - Rua São Francisco Xavier, 524, $1^{\circ}$ andar

bloco D, sl.1001 • Tels.: +55 21 2334-4088/4087 • http://www.e-publicacoes.uerj.br/index.php/polemica/index

http://www.labore.uerj.br • laboreuerj@yahoo.com.br 
GARCIA-ROZA, L.A. Pulsão. In: .Introdução à Metapsicologia Freudiana 3. Rio de Janeiro: Jorge Zahar Ed, 1995.

GORDON, P.; GLAUBER, H. K.; SALLET, P. C. Aspectos do Acompanhamento Psiquiátrico de Pacientes Obesos sob Tratamento Bariátrico: revisão. Revista de Psiquiatria Cliníca, 2011;38(4):148-54.

GURFINKEL, D. Adicções: Paixão e Vício. São Paulo: Casa do Psicólogo, 2011.

Adicções: da Perversão da Pulsão à Patologia dos Objetos Transicionais. Psychê - Revista de Psicanálise, Vol. XI, nº 20, 2007, p.13-28. São Paulo. Universidade São Marcos. Disponível em:<http://redalyc.uaemex.mx/src/inicio/ArtPdfRed.jsp?iCve=30716918002>.Acesso em: 20 dez. 2012.

LASAGNI, V. Estado Psicológico de los Postulantes a CirugíaBariatrica. BMI- dezembro / 2012,2.3.1o (119125). Disponível em:<www.bmilatina.com>.Acesso em: 7jul. 2014.

LASCH, C. A Personalidade Narcísica de Nossos Dias. In: A Cultura do Narcisismo - A Vida Americana numa Era de Esperanças em Declínio. Rio de Janeiro: Imago, 1983.p.55-76.

LE BRETON, D. A Sociologia do Corpo. Petrópolis, RJ: Vozes, 2006.

Adeus ao Corpo: antropologia e sociedade. Campinas: Papirus, 2003.

MATTOS, M.I.P. Os Transtornos Alimentares e a Obesidade numa perspectiva Contemporânea: Psicanálise e Interdisciplinaridade. Contemporânea - Psicanálise e Transdisciplinaridade, Porto Alegre, n.02, Abri/Mai/Jun 2007. Disponível em: <www.contemporaneo.org.br/contemporanea.php>. Acesso em: 10 jan. 2016.

NÉSPOLI, N; NOVAES, J. V \& ROSA, C. M. O Corpo na Cultura: obesidade como doença, biopolítica e normalização.Desafios: Revista Interdisciplinar da Universidade Federal do Tocantins,v. 1, n. 02., p. 149168, jan/jun. 2015.

NOVAES, J. de V. O Intolerável Peso da Feiúra. Sobre as mulheres e seus corpos. Rio de Janeiro: Ed.PUCRio,Garamond, 2013.

Com que corpo eu vou? Sociabilidade e usos do corpo nas mulheres das camadas altas e populares. Rio de Janeiro: Ed. PUC/Pallas, 2010.

PINHEIRO, N. N.; VILHENA, J. Entre o Público e o Privado: a clínica psicanalítica no ambulatório hospitalar. Arquivos Brasileiros de Psicologia, Rio de Janeiro, v.59, n.2, p.201-216, dez.2007. Disponível em:<http://pepsic.bvsalud.org/scielo.php?script=sci_arttext\&pid=S180952672007000200010\&Ing=pt\&nrm=iso>. Acesso em: 22 dez.2015.

RÍOS MARTINEZ. B.P; FUEYO M. A. ThePsychologist's Role in MetabolicSurgery. BMI Latina-2012,2.3.12. p.161-164.

ROMANO, B. W. Princípios para a Prática da Psicologia Clínica em Hospitais. São Paulo: Casa do Psicólogo, 1999.

SAROLDI, N. Mal Estar na Civilização - as obrigações do desejo na era da globalização. São Paulo. Ed: Civilização Brasileira, 2011.

VILHENA, J.; NOVAES, J. de V.; ROCHA, L.Comendo, comendo e não se satisfazendo: apenas uma questão cirúrgica? Obesidade mórbida e o culto ao corpo na sociedade contemporânea. Revista Mal-Estar Subjetividade, Fortaleza, v. 8, n. 2, jun. 2008.

\section{POLÊM!CA $\mid$ LABORE}


Recebido em: 24/04/2016.

Aceito em: 20/05/2016.

\section{POLÊM!CA $\mid$ LABORE}

Polêmica - Revista Eletrônica da Uerj - Rua São Francisco Xavier, 524, $1^{\circ}$ andar bloco D, sl.1001 • Tels.: +55 21 2334-4088/4087 • http://www.e-publicacoes.uerj.br/index.php/polemica/index http://www.labore.uerj.br • laboreuerj@yahoo.com.br 